\title{
Chemistry of conjugation to gold nanoparticles affects G-protein activity differently
}

\author{
Vibha Singh ${ }^{1}$, Santhosh P Nagappan Nair ${ }^{2^{*}}$ and Gopala Krishna Aradhyam ${ }^{1^{*}}$
}

\begin{abstract}
Background: Gold nanoparticles (AuNP) are extensively used as biophysical tools in the area of medicine and technology due to their distinct properties. However, vivid understanding of the consequences of biomoleculenanomaterial interactions is still lacking. In this context, we explore the affect of conjugation of $\mathrm{Ga}_{\mathrm{i} 1}$ subunit (of heterotrimeric G-proteins) to AuNP and examine its consequences. We consider two bio-conjugation strategies covalent and non-covalent binding.

Results: Affinity of the AuNP to the $\mathrm{Ga}_{\mathrm{i} 1}$ is $7.58 \times 10^{12} \mathrm{M}^{-1}$. AuNP conjugated $\mathrm{Ga}_{\mathrm{i} 1}$ exhibits altered kinetics of activation, non-covalent bio-conjugates displays retarded kinetics, up to 0.88 fold when GTPYS was used as ligand, of protein activation contrary to covalent conjugates which accelerates it to $\sim 5$ fold. Conjugation influence intrinsic Gai1 GTPase function in conflicting modes. Non-covalent conjugation inhibits GTPase function (decrease in activity upto 0.8 fold) whilst covalent conjugation drastically accelerates it (12 fold increase in activity). Altered basal nucleotide uptake in both types of conjugates and GTPase function in non-covalent conjugate are almost comparable except for GTPase property of covalent conjugate. The effect is despite the fact that conjugation does not change global conformation of the protein.

Conclusion: These findings provide clear evidence that nanoparticles, in addition to 'passive interaction' with protein (biomolecule), can interact "actively" with biomolecule and modify its function. This concept should be considered while engineering nanoparticle based delivery systems in medicine.
\end{abstract}

Keywords: G-protein, Nanoparticles, Fluorescence, Bioconjugation

\section{Background}

Impressive developments have occurred in nanoscience technology in the past decade, despite which a detailed understanding of nanoparticle (NP) interaction at cellular, sub-cellular and biomolecule level is lagging behind [1-19]. Cedervall et al. have demonstrated that binding and dissociation parameters of protein-nanoparticle complex depend on surface characteristics of nanoparticle as well as physico-chemical properties of the protein [20]. It has been demonstrated that NPs can elevate the rate of protein fibrillation potentially leading to proposals of novel mechanisms for amyloid diseases offering therapeutic opportunities for treatment [21]. Further, imaging studies provide crucial information that nano-conjugation uniformly

\footnotetext{
*Correspondence: santhosh@physics.iitm.ac.in; agk@iitm.ac.in ${ }^{2}$ Department of Physics, Indian Institute of Technology Madras, Chennai 600036, India

${ }^{1}$ Department of Biotechnology, Indian Institute of Technology Madras, Chennai 600036, India

Full list of author information is available at the end of the article
}

promotes endocytosis of EGFR, influencing its compartmentalization, and the mechanism of endocytosis [22]. Thus, nano-conjugation cannot be construed as an innocuous tool but may directly alter the cellular processes at the molecular level [22]. Improved understanding of the interactions at nano-bio interface will give answers to questions concerning the effect of conjugation on protein conformation and hence its function.

Majority of the drugs target GPCR, which transduce signal by activating heterotrimeric G-protein which in turn switches on a cascade of downstream signal transduction pathway. The activation status of heterotrimeric $G$ protein regulates the downstream cascade events. Hence, $\mathrm{G \alpha}_{\mathrm{i} 1}$ is a very important model protein to investigate the effects of different types of conjugation to nanoparticle. G proteins are ubiquitously expressed and despite the variety in their function and biochemical effects, their structures are very highly conserved. These properties of $\mathrm{G}$ proteins, additionally, make them very vital model systems for studying the effects of

\section{Biomed Central}


nanoparticles; an area that is fast gaining importance in biology and medicine.

In the present study, we investigate the effect of the different conjugation strategies on the conformation and function of $\mathrm{G}$ proteins. A comparative study is presented, between non-covalently and covalently bound AuNP-G $\alpha_{i 1}$ conjugates. In the non- covalent conjugate, the rate of basal nucleotide uptake was retarded in a concentration dependent manner of AuNP, whereas in the covalent conjugate, the rate was accelerated. Both types of conjugation influenced the intrinsic $\mathrm{G \alpha}_{\mathrm{i} 1}$ GTPase function affecting the kinetics of GTP hydrolysis in opposite modes. Noncovalent conjugation showed inhibitory effect on GTPase function whilst covalent conjugation dramatically accelerated it. We propose that the mode of interaction with nanoparticles modulate the function of the protein in the conjugate, which may alter related cellular physiological pathways. These findings provide strong evidence that nanoparticles can interact "actively" with biomolecules and modify their function.

\section{Results}

Bio-conjugation exploiting two different approaches

In this study two linkage strategies have been used for the conjugation of AuNPs to $G \alpha_{i 1}$. Dihydrolipoic acid (DHLA) capped AuNPs of hydrodynamic diameter $6 \mathrm{~nm}$ was used in the entire study. Interaction studies were performed in a buffer at $\mathrm{pH} 8.0$ with low ionic strength $(10 \mathrm{mM} \mathrm{NaCl})$, since conjugates exhibited a tendency to aggregate at higher ionic strength [23].

\section{(i) N-terminal covalent conjugation using EDC} chemistry: Site specific conjugation was achieved by forming a peptide bond between $\mathrm{N}$-terminal primary amine of the protein and carboxylic acid groups of negatively charged AuNP utilizing 1-Ethyl-3-[3dimethylaminopropyl] carbodiimide, EDC, chemistry. Retardation of AuNP's electrophoretic mobility on agarose gel confirmed conjugation (Additional file 1: Figure S1A). Negative control (AuNP in presence of EDC without protein) also exhibited negligibly small amount of retardation in mobility due to the formation of $\mathrm{O}$-acylisourea intermediate between AuNP and EDC. Changes in mobility of $\mathrm{Au}: \mathrm{G \alpha}_{\mathrm{i} 1}$ complex depends on the concentration of EDC used.

(ii)Non-covalent conjugation: In non-covalent conjugation AuNP capping ligand plays an important role in the bio-conjugate. In the present study, AuNP is capped with DHLA which gives an overall negative charge on its surface. The protein may interact with AuNP in a number of orientations, or many AuNP's could be attached to a given molecule of protein. Non-covalently bound protein-NP complex was also retarded in electrophoretic mobility, compared to
AuNP itself (Additional file 1: Figure S1B), confirming their conjugation. To explore further, whether the conjugation was cysteine mediated, $\mathrm{G \alpha}_{\mathrm{i} 1}$ sulfhydryl groups were modified using Iodoacetamide.

Conjugation to AuNP was observed even with cysteine modified $\mathrm{G \alpha}_{\mathrm{i} 1}$ (Additional file 1: Figure S1B), as evidenced by retardation in its electrophoretic mobility. Mobility of $\mathrm{G \alpha}_{\mathrm{i1}}$-AuNP and cysteine-modified-G $\alpha_{\mathrm{i1}}{ }^{-}$ AuNP were similar, ruling out cysteine mediated interaction between AuNP and $G \alpha_{i 1}$. To further demonstrate that non-specifically conjugated $\mathrm{G \alpha}_{\mathrm{i} 1}$ has free sulphydryl groups, N-(3-pyrene) maleimide (NPM) was used to check formation of fluorescent adducts with free thiol groups (Additional file 2: S2). Cysteinemodified $\mathrm{G \alpha}_{\mathrm{i} 1}$-AuNP, upon treatment with NPM displayed fluorescence spectrum with peaks at $377 \mathrm{~nm}$, $397 \mathrm{~nm}$ and $418 \mathrm{~nm}$ similar to $\mathrm{G \alpha}_{\mathrm{i} 1}-\mathrm{NPM}$ adduct, though, with a lesser intensity. These results confirm the presence of free sulphydryl groups of $\mathrm{G \alpha}_{\mathrm{i} 1}$ even after non specific conjugation with AuNPs.

\section{Quenching of $\mathrm{Ga}_{\mathrm{i} 1}$ Tryptophan fluorescence by AuNP}

Tryptophan fluorescence of $\mathrm{G \alpha}_{\mathrm{i} 1}$ was quenched by AuNP in a dose-dependent (0.1-0.5 nM) manner (Figure 1).

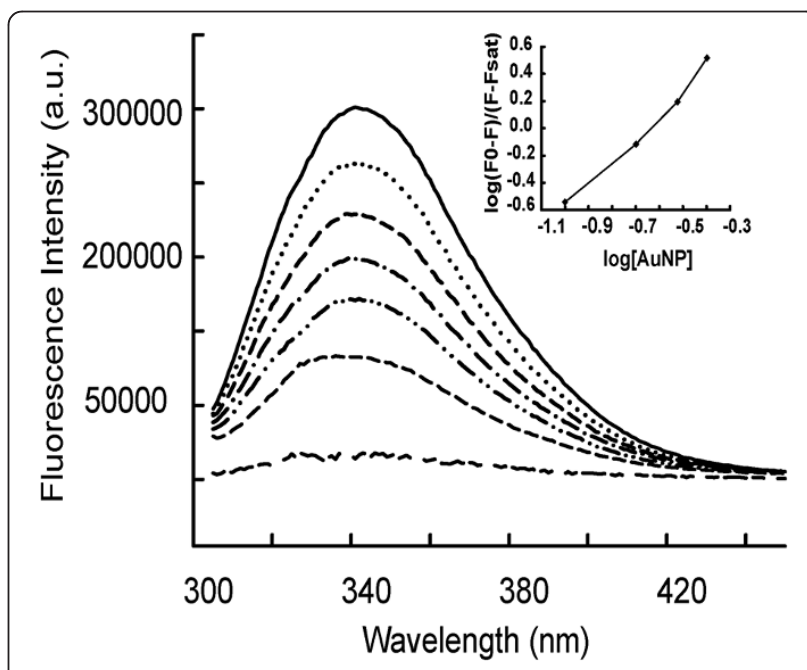

Figure 1 Effect of AuNP on steady state Tryptophan

fluorescence from $\mathrm{Ga}_{\mathrm{i} 1}$ in inactive state. In order to monitor the effect of non-covalent interaction of AuNP and Gail, intrinsic tryptophan steady state fluorescence was monitored. A final concentration of $400 \mathrm{nM} \mathrm{Ga} i 1$ in $5 \mathrm{mM}$ Hepes- $\mathrm{Na}$ (pH 8.0), $10 \mathrm{mM}$ $\mathrm{NaCl}, 0.5 \mathrm{mM} \mathrm{MgCl}_{2}, 1 \mu \mathrm{M} \mathrm{GDP}$ was used to monitor the spectrum in all the experiments. The solid line represents $0 \mathrm{nM}$ AuNP; dotted line represents $0.05 \mathrm{nM}$ AuNP; dashed line represents $0.1 \mathrm{nM}$ AuNP; dash-dot-dash line represents $0.2 \mathrm{nM}$ AuNP; dash-dot-dot line represents $0.3 \mathrm{nM}$ AuNP; Short dash-short dash line represents 0.4 nM AuNP; short dash-long dash line represents 0.5 nM AuNP. Inset displays the double-logarimithic plot of the quenching of Gai1 tryptophan fluorescence related to addition of AuNP. Spectra are representative and experiments were repeated several times. All the spectra were recorded at $25^{\circ} \mathrm{C}$. 
No shift was observed in the $\lambda_{\text {max,em }}$ of tryptophan $G \alpha_{i 1}-$ AuNP conjugate formation, indicating that the polarity of tryptophan environment, and hence the overall protein structure did not change upon conjugation. The binding constant $\left(K_{b}\right)$ and the numbers of binding sites $(n)$ between AuNPs and $G \alpha_{i 1}$ were determined using the method described by Tedesco et al., [24] as $7.58 \times 10^{12} \mathrm{M}^{-1}$ and 1.2 respectively, from the fluorescence spectral titration.

\section{Rate of activation is differentially affected by the nature of conjugation}

Fluoroaluminates activate $\mathrm{G \alpha}_{\mathrm{i} 1}$-GDP by mimicking the $\gamma$ phosphate of GTP in its binding site. Time dependent fluorescence changes from $\mathrm{G \alpha}_{\mathrm{i} 1}$ upon activation by $\mathrm{AlF}_{4}^{-}$ binding was monitored for non-covalent and covalent AuNP conjugated $\mathrm{Go}_{\mathrm{i} 1}$ and activation rates were calculated.

(i) Non-covalent conjugation: Attenuation in the rate of activation accompanied with decrease in values of maximum plateau in fluorescence by $\mathrm{AlF}_{4}^{-}$were observed with to non-covalent complex of $\mathrm{Au}: \mathrm{G \alpha}_{\mathrm{i} 1(\mathrm{GDP})}$. The effect was AuNP concentration dependent, with total loss of activity at $0.4 \mathrm{nM} \mathrm{AuNP}$ for $200 \mathrm{nM} \mathrm{G \alpha} \alpha_{\mathrm{i} 1}$ (Figure 2A, Table 1).

(ii) Covalent conjugation: Conversely, covalent conjugation at the $\mathrm{N}$-termini of the protein caused enhancement in the rate of $\mathrm{AlF}^{4-}$ mediated activation, 3.2 fold in comparison to unconjugated protein (Figure 2B, Table 1).

Both non-covalently and covalently bound AuNP did not perturb the characteristic feature of $\mathrm{Go}_{\mathrm{i} 1}$ to bind GDP nucleotide and its behaviour to undergo activationdependent changes induced by transition state mimetic, $\mathrm{AlF}_{4}^{-}$. Non-covalent and covalent conjugation, modulated kinetics of $\mathrm{AlF}_{4}^{-}$induced activation of $\mathrm{Go}_{\mathrm{i} 1}$ in contrasting manner. The rate of activation by $\mathrm{AlF}_{4}^{-}$is much faster in case of covalently conjugated protein and the peak fluorescence of active protein was comparable with respect to unconjugated protein (Figure 2).

\section{Conjugation does not affect the secondary structure of the protein}

Far-UV Circular Dichroism (CD) spectra were recorded to monitor secondary structural features of the protein. Noncovalent or covalent conjugation with AuNP did not cause changes in secondary structure of the protein suggesting the global structure of complex of $A u: G \alpha_{i 1(G D P)}$ to be intact (Additional file 3: Figure S3). These findings clearly indicate that the conjugation of AuNP changes the activity of $G \alpha_{i 1}$ without affecting the conformation of the protein.

\section{Mode of interaction between $\mathrm{Ga}_{\mathrm{i} 1}$ and AuNP alter the kinetics of basal GTPץS binding}

Next, we investigated whether functionalization of $\mathrm{Ga}_{\mathrm{i} 1}$ with AuNP affects the basal nucleotide exchange rate, the

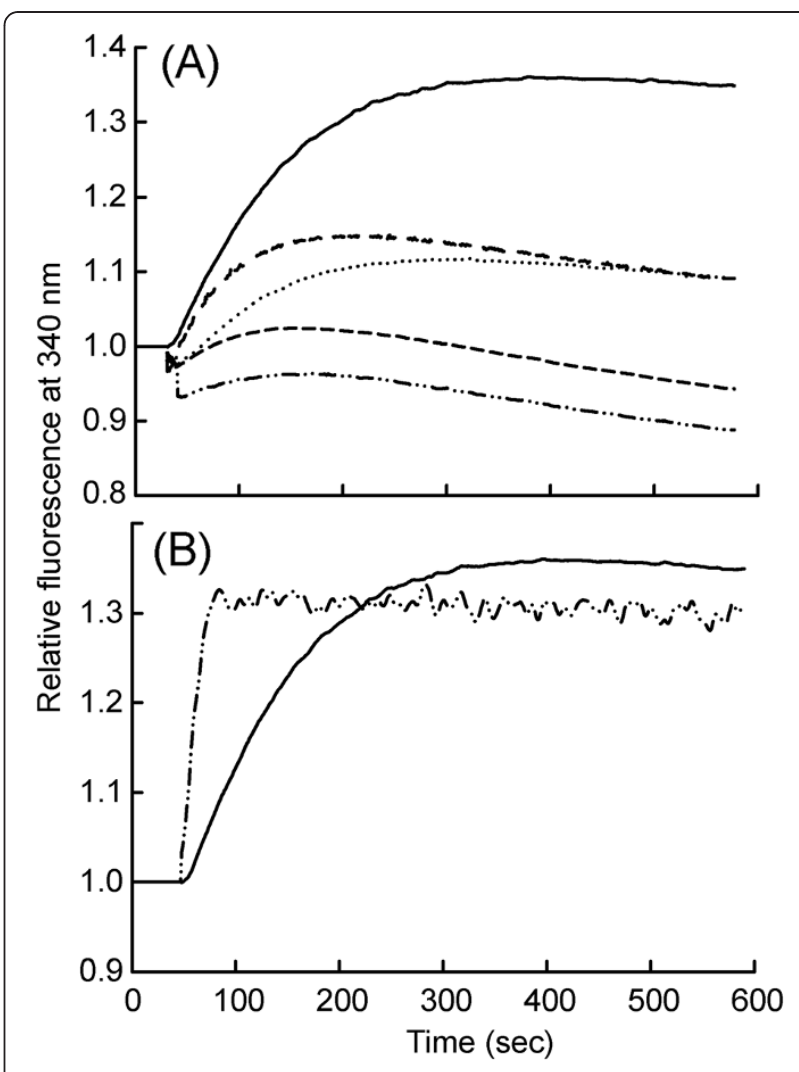

Figure 2 Time course $\mathrm{AlF}^{4-}$ mediated $\mathrm{Ga}_{\mathrm{i} 1}$ activation of bioconjugated AuNP- $\mathrm{Ga}_{\mathrm{i} 1}$. (A) Demonstrates effect of noncovalent interaction of AuNP- $\mathrm{Ga}_{\mathrm{i} 1}$ on rate of $\mathrm{AlF}^{4-}$ binding to $\mathrm{Ga}_{\mathrm{i} 1^{-}}$ GDP. Solid line represents 0 nM AuNP (only protein); Short dashshort dash line represents $0.1 \mathrm{nM}$ AuNP; dotted line represents 0.5 nM AuNP; dashed line represents 0.75 nM AuNP; dash-dot-dot line represents $1 \mathrm{nM}$ AuNP. (B) Demonstrates effect of $\mathrm{N}$-terminal covalent conjugation of $\mathrm{Ga}_{\mathrm{i} 1}$ to AuNP via EDC reaction on $\mathrm{AlF}^{4-}$ binding to AuNP- $\mathrm{Ga}_{\mathrm{i} 1}-\mathrm{GDP}$. The solid line represents $\mathrm{Ga}_{\mathrm{i} 1}$ without any conjugation (control); the dash-dot-dot line represents conjugated AuNP- $\mathrm{Ga}_{\mathrm{i} 1}$. For all the time course fluorescence measurement final concentration of $200 \mathrm{nM}$ of $\mathrm{Ga}_{\mathrm{i} 1}$ (conjugated and purified $200 \mathrm{nM}$ AuNP- $\mathrm{Ga}_{\mathrm{i} 1}$ in case of covalent conjugation) was taken in a quartz cuvette containing $5 \mathrm{mM}$ Hepes- $\mathrm{Na}$ (pH 8.0), $10 \mathrm{mM} \mathrm{NaCl}, 0.5 \mathrm{mM} \mathrm{MgCl}, 1 \mu \mathrm{M}$ GDP. In case of experiments performed in panel A, appropriate amounts of AuNP-DHLA (in $5 \mathrm{mM}$ Hepes- $\mathrm{Na}(\mathrm{pH}$ 8.0)) were mixed with protein and incubated for 10 minutes. Tryptophan emission at $340 \mathrm{~nm}$ was monitored by exciting the sample at $295 \mathrm{~nm}$ with continuous stirring. $2 \mathrm{mM} \mathrm{NaF}$ and subsequently followed by $20 \mu \mathrm{M} \mathrm{AlCl}_{3}$ was added to the reaction and relative fluorescence was monitored as a function of time. All the measurements were performed at $25^{\circ} \mathrm{C}$. Non-covalently conjugated AuNP- $\mathrm{Ga}_{i 1}$ displayed deaccelerated rates of basal AIF ${ }^{4-}$ binding to $\mathrm{Ga}_{11}$-GDP. Non covalent conjugates decreased $\mathrm{AlF}^{4-}$ binding upto 0.08 fold. On the contrary N-terminal covalent conjugation caused 3.2 fold increase in rate of $\mathrm{AlF}^{4-}$ binding. The Plateau fluorescence intensity of covalently conjugated AuNP- Ga $a_{i 1}$ was comparable to only Gai1, whereas non-covalent conjugation displayed decrease in plateau fluorescence in a concentration dependent manner. 
Table 1 Effect of AuNP on basal rate constants of Gai1-AIF4- binding

\begin{tabular}{ccc}
\hline Non-Covalent AuNP-Gai1 [AuNP] $\mathbf{n M}$ & $\boldsymbol{k}_{\text {app }}\left(\mathbf{s e c}^{-1}\right)$ & Fold change \\
\hline 0 & 2.74 & - \\
\hline 0.1 & 2.34 & 0.85 \\
\hline 0.5 & 1.12 & 0.43 \\
\hline 0.75 & 0.004 & 0.17 \\
\hline 1 & 0.003 & 0.08 \\
\hline Covalent AuNP- Gai1 & 8.8 & 3.2 \\
\hline
\end{tabular}

in vivo activity of the protein. Nucleotide exchange (GDP to $\mathrm{GTP} \gamma \mathrm{S}$ ) by $\mathrm{G \alpha}_{\mathrm{i} 1}$, upon covalent and non-covalent conjugation of AuNP, was monitored by measuring the enhancement in intrinsic Trp fluorescence. Changes in fluorescence were monitored as a function of time after addition of GTPYS (Figure 3, Table 2). Non-covalent conjugation led to a drop in the basal rate of GTPYS uptake, while covalent conjugation caused an increase of $\sim 5$ fold in the rate of GTPYS uptake. Rate of GTPYS uptake by both types of AuNP:G $\alpha_{\mathrm{i} 1(\mathrm{GDP})}$ complexes corroborated $\mathrm{GDP} / \mathrm{AlF}_{4}^{-}$activation data. Both results provide evidence for dependence of functional behaviour of conjugates on the nature of interaction between AuNP and $\mathrm{G \alpha}_{\mathrm{i} 1}$, as the conjugates preserved the native conformation confirmed by far UV CD analysis.

\section{AuNP conjugation modulates $\mathrm{Ga}_{\mathrm{i} 1}$ intrinsic GTPase activity}

We used an extrinsic fluorescent probe, $\mathrm{N}^{\prime}$ - Methylan thraniloyl (mant)-GTP (mGTP) in order to quantitatively study effect of AuNP conjugation on binding and release of nucleotide (GTP/GDP) and monitor $G \alpha_{i 1}$ activation. Fluorescence resonance energy transfer (FRET) was monitored as a function of time by exciting the intrinsic tryptophan fluorescence at $295 \mathrm{~nm}$ and measuring the mGTP fluorescence at $448 \mathrm{~nm} .200 \mathrm{nM} \mathrm{G \alpha} \alpha_{\mathrm{i} 1}$ was titrated with several concentration of mGTP (100 nM to $800 \mathrm{nM}$ ). mGTP fluorescence increased upon addition to $\mathrm{G \alpha}_{\mathrm{i} 1}$ and then decayed at a slower rate, confirming mGTP hydrolysis to mGDP. Further, addition of $10 \mu \mathrm{M}$ GTP $\gamma$ S decreased the mGDP fluoresecence rapidly. To obtain the corrected mGTP uptake and hydrolysis, fluorescence remaining after GTPYS addition was subtracted.

Non-covalent conjugation of $\mathrm{G \alpha}_{\mathrm{i} 1}$ with AuNP retarded the basal exchange rate of mGTP to protein bound GDP, up to 0.4 fold, in a concentration dependent manner of AuNP (Figure 4A, Table 3) Altered $\mathrm{G \alpha}_{\mathrm{i} 1}-\mathrm{NP}$ basal nucleotide uptake convincingly demonstrates AuNP influence of the mode of binding. Further, to investigate the effect of AuNP conjugation on $\mathrm{G \alpha}_{\mathrm{i} 1}$ GTPase function mGTP hydrolysis kinetics was monitored. Significant decrease in mGTP hydrolysis rate (Figure 5A) was observed (Table 4), suggesting the non-covalent binding with AuNP has an

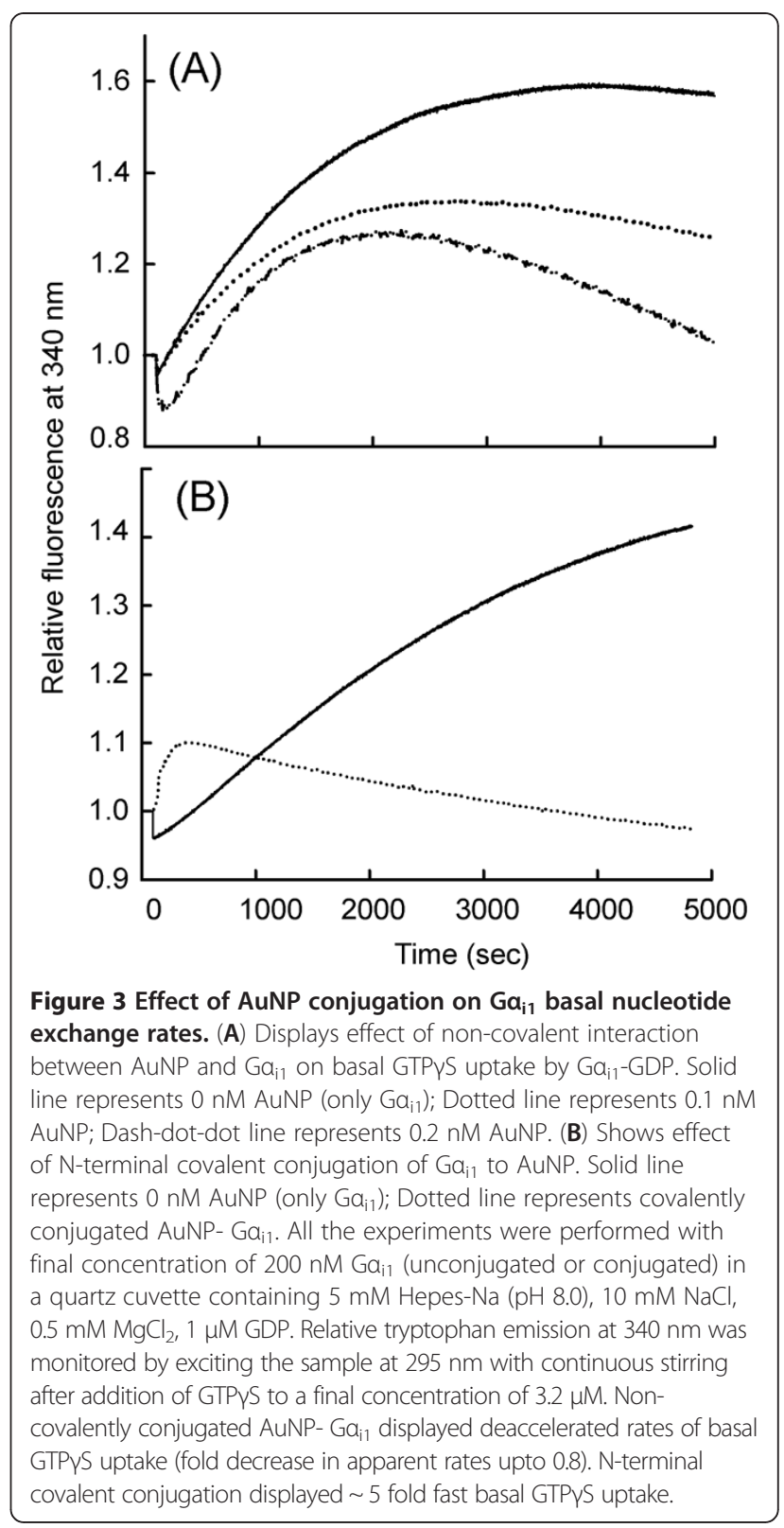

inhibiting effect on intrinsic GTPase property of $\mathrm{G \alpha}_{\mathrm{i} 1}$. Covalent conjugation of $\mathrm{G \alpha}_{\mathrm{i} 1}$ with AuNP resulted in 12 fold increase in GTPase activity (Figure 4B). This indicates that covalent conjugation of AuNP to $\mathrm{G \alpha}_{\mathrm{i} 1}$ has an accelerating effect on intrinsic GTPase function of $G \alpha_{i 1}$.

Table 2 Effect of AuNP conjugation on $\mathrm{Ga}_{\mathrm{i} 1}$ basal GTPYS uptake

\begin{tabular}{ccc}
\hline Non-Covalent AuNP- $\mathrm{Ga}_{\mathrm{i} 1}$ [AuNP] $\mathbf{n M}$ & $\boldsymbol{k}_{\text {app }}\left(\mathbf{s e c}^{-\mathbf{1}}\right)$ & Fold change \\
\hline 0 & 0.4 & - \\
0.1 & 0.30 & 0.75 \\
0.2 & 0.35 & 0.87 \\
Covalent AuNP- $\mathrm{Ga}_{\mathrm{i} 1}$ & 1.9 & 4.75 \\
\hline
\end{tabular}




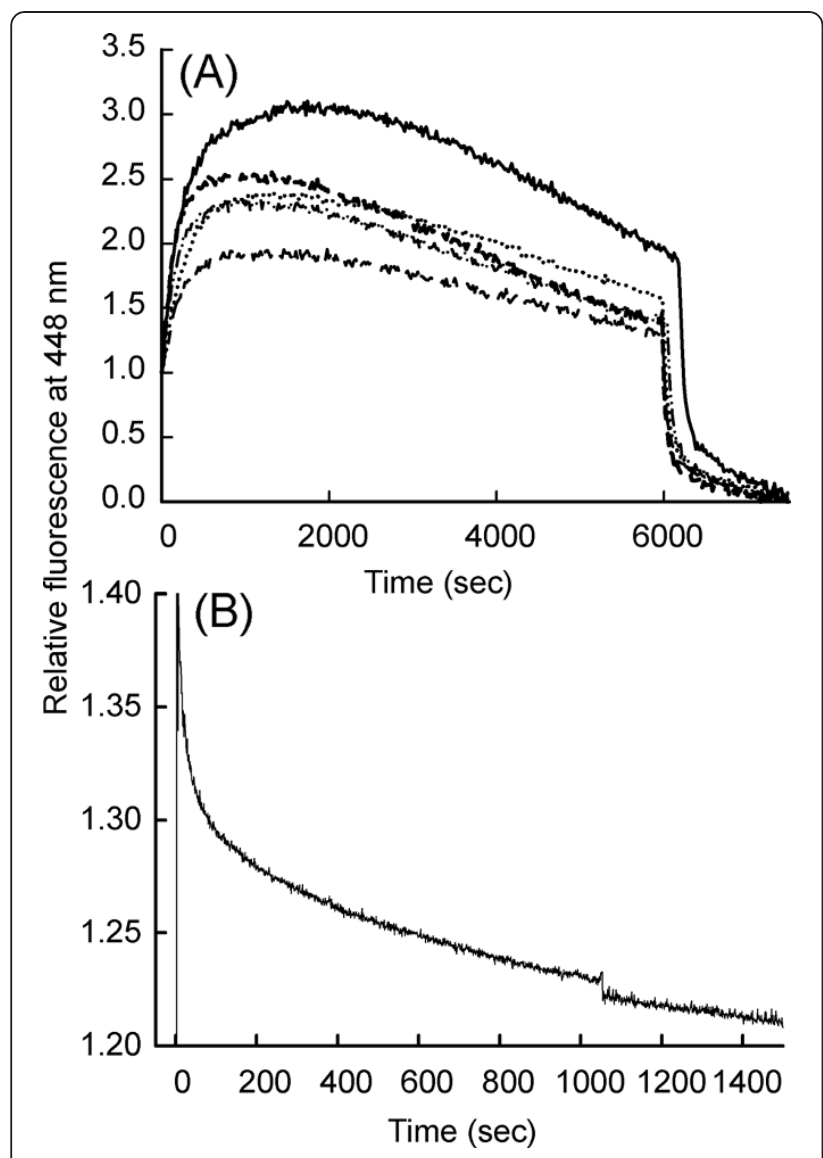

Figure 4 FRET based time course measurement to study effect of AuNP conjugation on $\mathrm{Ga}_{\mathrm{i} 1}$ basal nucleotide uptake and hydrolysis. Fluorescently-labeled nucleotide (mant-GTP) was used to do FRET studies for monitoring rates of nucleotide exchange. (A) Displays effect of non-covalently conjugated AuNP- $\mathrm{Ga}_{\mathrm{i} 1}$ on FRET based measurements. The solid line represents 0 nM AuNP; Short-short-short line represents $0.1 \mathrm{nM}$ AuNP; Dash-dot-dash line represents $0.2 \mathrm{nM}$ AuNP; Dotted line represents $0.3 \mathrm{nM}$ AuNP; Long-short line represents $0.4 \mathrm{nM}$ AuNP. (B) Displays effect of $\mathrm{N}$-terminal covalent conjugation on FRET based measurements. The solid line represents covalently conjugated AuNP-Gai1. In all the experiments, a final concentration of $200 \mathrm{nM} \mathrm{Ga} \mathrm{i}_{11}$ was taken in a quartz cuvette containing $5 \mathrm{mM}$ Hepes- $\mathrm{Na}$ ( $\mathrm{pH}$ 8.0), $10 \mathrm{mM} \mathrm{NaCl}, 0.5 \mathrm{mM} \mathrm{MgCl}_{2}$, and $1 \mu \mathrm{M}$ GDP. Time course FRET was monitored by exciting the protein intrinsic tryptophan $\left(\lambda_{\text {ex }}\right.$ $295 \mathrm{~nm}, \lambda_{\mathrm{em}} 340 \mathrm{~nm}$ ) and monitoring fluorescence from MANT ( $\lambda_{\text {ex }} 355 \mathrm{~nm}, \lambda_{\mathrm{em}} 448 \mathrm{~nm}$ ). $700 \mathrm{nM}$ MANT-GTP was added and relative increase in fluorescence was monitored as a function of time. At 6000 seconds, $10 \mu \mathrm{M}$ GTPYS was added to the reaction mixture. The fluorescence remaining after addition of GTPYS was subtracted from the data. Non-covalent interaction resulted in retardation in basal $\mathrm{Ga}_{\mathrm{i} 1}$ mGTP uptake in a AuNP concentration dependent manner.

\section{Discussion}

In the present study, we address the dependence on the chemistry of conjugation towards alteration in the kinetics of activation of $\mathrm{G \alpha}_{\mathrm{i} 1}$. There have been contradicting observations regarding the benefit of using a nanoparticle in
Table 3 Effect of AuNP conjugation on $\mathrm{Ga}_{\mathrm{i} 1}$ basal mGTP uptake

\begin{tabular}{ccc}
\hline Non-Covalent AuNP- $\mathbf{G a}_{\mathbf{i} 1}$ [AuNP] $\mathbf{n M}$ & $\boldsymbol{k}_{\text {app }}\left(\mathbf{s e c}^{-\mathbf{1}}\right)$ & Fold change \\
\hline 0 & 7.6 & - \\
\hline 0.1 & 7.5 & 0.98 \\
\hline 0.2 & 6.0 & 0.80 \\
\hline 0.3 & 4.0 & 0.53 \\
\hline 0.4 & 3.3 & 0.44 \\
\hline
\end{tabular}

medicine and biochemistry [25-27]. In our view, understanding the physico-chemical basis of how an engineered nanoparticle modulates biological processes requires the study of nanoparticle-biomolecule binding and its effects on biomolecule functionality. Recent studies have emphasized that properties like size, shape, surface modification, and charge of nanoparticles can profoundly affect the interaction between NPs and biomolecules.

Guanine nucleotide binding proteins (G-protein) play a vital role in the physiology of a cell. Structure-function relationship of both, the monomeric and the heterotrimeric $\mathrm{G}$ proteins are well understood, their crystal structures helping elucidate their mode of action and the biochemical function. Heterotrimeric G-proteins are activated by agonist-stimulated G Protein-Coupled Receptors (GPCRs) that catalyze the exchange of GTP for GDP on G protein $\alpha$-subunits and relay extracellular signal to intracellular signalling pathways [28]. We chose to use G proteins as model proteins to better understand the effect of AuNP binding to proteins and the biological effect they elucidate.

Here, we exploit two modes of conjugation between $\mathrm{G \alpha}_{\mathrm{i} 1}$ and AuNP, covalent and non-covalent. Effect of AuNP conjugation to $\mathrm{G \alpha}_{\mathrm{i} 1}$ was examined by monitoring steady-state Trp-fluorescence from the protein. AuNP interacts with $\mathrm{G \alpha}_{\mathrm{i} 1}$ with a binding constant $\left(\mathrm{K}_{\mathrm{b}}\right)$ of $7.58 \times 10^{12} \mathrm{M}^{-1}$. Strong tryptophan fluorescence quenching of $G \alpha_{i 1}$ was observed with increasing concentration of AuNP. Fluorescence quenching could be explained by efficient energy transfer between AuNP and $\mathrm{G \alpha}_{\mathrm{i} 1}$ tryptophan residues. No shift in emission wavelength was noticed, suggesting no change in polarity around tryptophan residues on addition of AuNPs.

Cysteine modifications did not alter the AuNP conjugation and, vice versa, conjugation did not lead to the unavailability of the thiol groups of cysteine for the modifying reagents, therefore leading us to conclude that the 10 cysteine residues (of $\mathrm{G}_{\mathrm{i} 1}$ ) do not interact with AuNP via thiol$\mathrm{Au}$ linkage chemistry. Our finding is in agreement with a previous study which demonstrates that cysteine residue at the end of a $\mathrm{C}$-terminus of protein was much more reactive toward a gold cluster than a cysteine residue introduced in middle region of protein [29]. This study concludes that non-specific AuNP interaction is not protein-sulphydryl mediated even though cysteine residues are present on $\mathrm{G \alpha}_{\mathrm{i} 1}$ surface. 


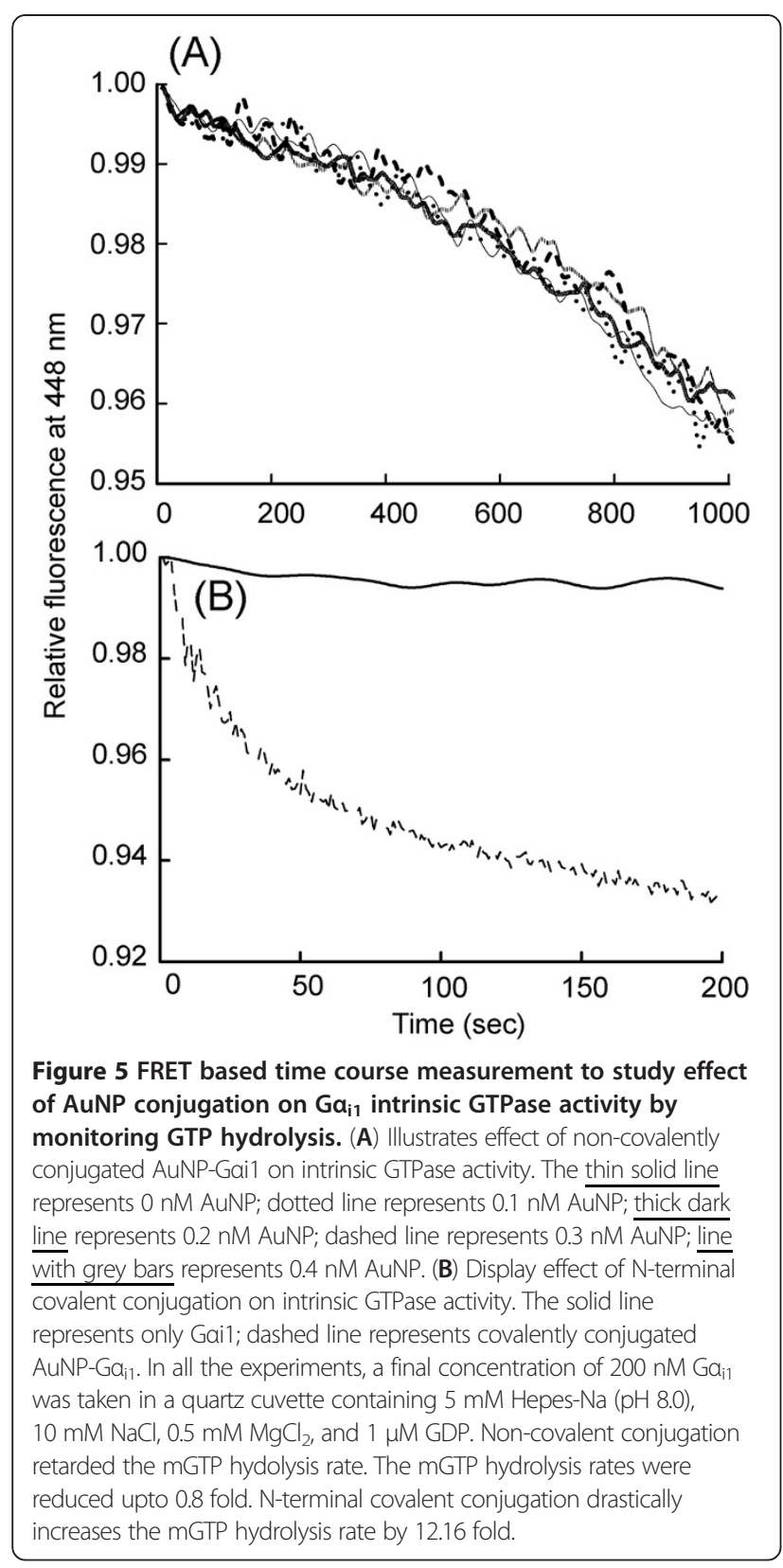

A number of studies have shown that nanoparticle protein conjugates undergo conformational changes and result in unfolding of protein [30-32]. For biochemical applications of NP-protein conjugates, it is crucial that labelling does not modify the protein structure. Interestingly, both types of conjugates of $G \alpha_{i 1}$ retain their secondary structure as evident from far UV-CD spectra profile for $\mathrm{G \alpha}_{\mathrm{i} 1}$ and the conjugates (Additional file 3: Figure S3).

We next investigated whether the bioconjugated $G \alpha_{i 1}$ was functional and active. We report here functional activity of both the covalent and non-covalent AuNP conjugated $\mathrm{G \alpha}_{\mathrm{i} 1}$. Time dependent fluorescence measurement using intrinsic tryptophan and extrinsic MANT moiety
Table 4 Effect of AuNP conjugation on $\mathrm{Ga}_{\mathrm{i} 1}$ GTPase activity

\begin{tabular}{ccc}
\hline Non-Covalent AuNP- $\mathbf{G a}_{\mathbf{i} 1}$ [AuNP] $\mathbf{n M}$ & $\boldsymbol{k}_{\text {app }}\left(\mathbf{s e c}^{-\mathbf{1}}\right)$ & Fold change \\
\hline & 0.46 & - \\
\hline 0.1 & 0.43 & 0.934 \\
\hline 0.2 & 0.40 & 0.869 \\
\hline 0.3 & 0.40 & 0.869 \\
\hline 0.4 & 0.37 & 0.804 \\
\hline Covalent AuNP- $\mathrm{Ga}_{\mathrm{i} 1}$ & 4.5 & 12.16 \\
\hline
\end{tabular}

fluorescence with hydrolyzable and non-hydrolyzable nucleotides were assayed. Detailed kinetics based functional studies for both non-covalent and covalent AuNP-Ga $\alpha_{i 1}$ conjugates have provided important insights: (i) reduced rate of activation by $\mathrm{AlF}^{4-}, \mathrm{GTP} \gamma \mathrm{S}$ and mant-GTP were observed as a consequence of non-covalent interaction of AuNP. (ii) N-terminal covalent probing led to enhanced rate of nucleotide uptake "activity" of $\mathrm{G \alpha}_{\mathrm{i} 1}$.

To further probe the influence of AuNP conjugation on intrinsic $\mathrm{G \alpha}_{\mathrm{i} 1}$ GTPase function, kinetics of bound GTP hydrolysis was examined. As demonstrated in Figure 5A, non-covalent conjugation does not affect the GTPase function while covalent conjugation dramatically accelerated it. From our studies, it may be hypothesized that the functional property of conjugated protein are governed by the contribution of type of molecular interaction, between the nanomaterial and biomolecule (Figure 6). This has strong implication that nanoparticles can impair the cell function when it enters into biological fluid depending on the extent and format of presentation of the signalling protein to the nanoparticles. Thus, these finding presented here need

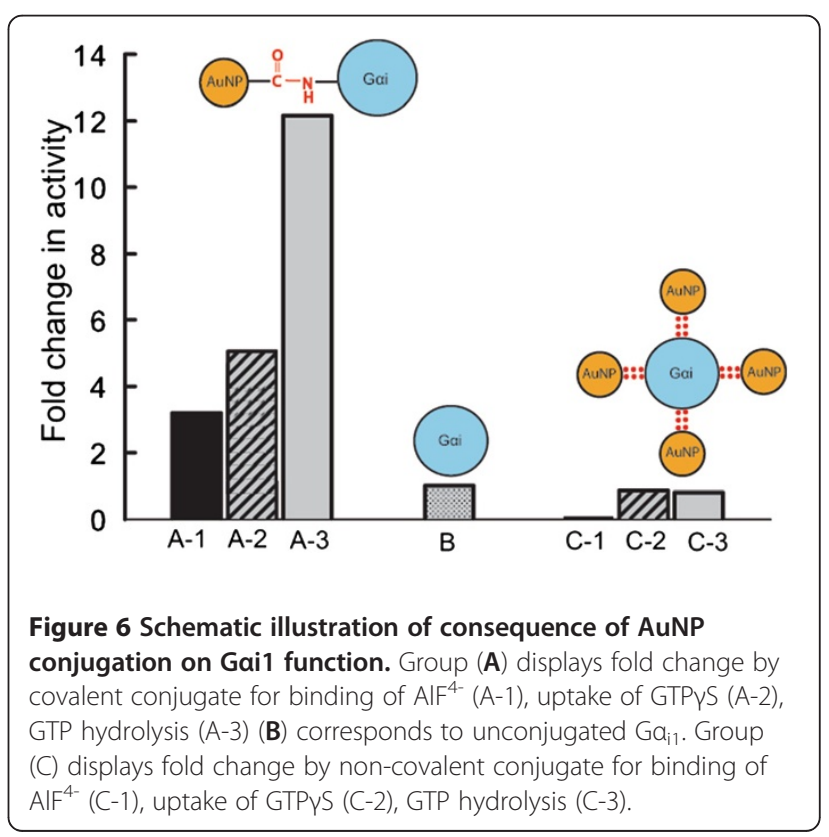


to be considered carefully before using engineered nanoparticles for medical application.

\section{Conclusion}

In summary, we here report two different bioconjugation strategies, non-covalent and covalent attachment, of $\mathrm{G \alpha}_{\mathrm{i} 1}$ to $6 \mathrm{~nm}$ DHLA capped AuNP. No effect of change in protein conformation was observed despite the presence of negatively charged capping ligand, DHLA. Non-covalent bioconjugation caused decrease in "activity" of $\mathrm{Go}_{\mathrm{i} 1}$ in terms of decelerated rate of nucleotide exchange and inhibited GTPase activity. N-terminal covalent probing of AuNP modulate the active state of $\mathrm{G \alpha}_{\mathrm{i} 1}$ state, as displayed by enhanced rate of nucleotide exchange and stimulated GTPase function. These results (extraordinary increase in the $G \alpha_{i 1}$ GTPase property) have ramification in understanding the probable molecular basis of gold to cure many diseases when used either in powder form (in ayurvedic treatment) or as colloidal gold in modern medicine (e.g., in arthritis).

\section{Methods \\ Materials}

All the chemicals used were purchased from SigmaAldrich, USA.

\section{Synthesis of Gold nanoparticles (AuNPs)}

The synthesis protocol of $6 \mathrm{~nm}$ gold nanoparticles is adopted from Nikhil and Xiaogang (2003) for a singlephase reaction (Additional file 4: S4) [33].

\section{Size and optical characterization of AuNP}

Transmission electron microscopy was used to visualise the shape and to determine size distribution of AuNPs (Additional file 5: Figure S5). TEM images were obtained using JEOL 3010, operating at $300 \mathrm{kV}$ accelerating voltage. The average size distribution was determined by using the image analysis software, Image J. The UV-vis absorption spectra were recorded on a Jasco V-660 UV-vis spectrometer at room temperature with $1 \mathrm{~cm}$ path length cuvette. Spectra were obtained with a band width of $1.0 \mathrm{~nm}$ and a scan rate of $40 \mathrm{~nm} /$ minutes (Additional file 6: Figure S6). Toluene was used as reference.

\section{Expression and purification of $\mathrm{Ga}_{\mathrm{i} 1}$ protein}

The DNA fragment containing the WT rat $\mathrm{Go}_{\mathrm{i} 1}$ subunit, cloned into the pET28b expression vector was used to transform BL21 (DE3) cells to express an N-terminal hexaHis-tag-WTGail protein in the presence of kanamycin $(100 \mu \mathrm{g} / \mathrm{mL})$ and purified (Additional file 7: S7). The eluted protein fractions with the maximum protein content were estimated by Lowry's method [34] and purity checked by SDS-PAGE. The average yield for WT Go $\alpha_{i 1}$ was $10 \mathrm{mg} / \mathrm{L}$ of culture.

\section{Bioconjugation}

(i) Non covalent conjugation: $100 \mu \mathrm{L}, 0.2 \mu \mathrm{M}$ purified AuNP-DHLA (in $5 \mathrm{mM}$ Hepes-Na, $\mathrm{pH}$ 8.0) was incubated with $100 \mu \mathrm{L}, 200 \mu \mathrm{M} \mathrm{G \alpha} \alpha_{i 1}$ at room temperature for 20 minutes. Unconjugated protein and free AuNP were removed by centrifugation $\left(12000 \mathrm{rpm}, 20\right.$ minutes $4^{\circ} \mathrm{C}$ ) (Additional file 1: Figure S1A).

(ii) Covalent bioconjugation: 1-Ethyl-3-[3-dimethylamino propyl] carbodiimide (EDC) was used as a cross linking agent between carboxyl groups of AuNP and primany amines of $\mathrm{Go}_{\mathrm{i} 1}$. For linkage, $100 \mu \mathrm{L} 3 \mathrm{mM}$ EDC (prepared in double distilled water) was added to $100 \mu \mathrm{L} 0.2 \mu \mathrm{M}$ AuNP and mixed. $100 \mu \mathrm{L}, 200 \mu \mathrm{M} \mathrm{G \alpha} \alpha_{i 1}$ was added to the mixture containing AuNP and EDC and incubated for 15 minutes at room temperature. Unbound protein and AuNP were removed by centrifugation (15 min, $14000 \mathrm{rpm}$ ). Gel electrophoresis was used to confirm conjugation (Additional file 1: Figure S1A).

\section{Fluorescence spectroscopy \\ Steady state fluoresecence}

Steady state intrinsic tryptophan fluorescence of $\mathrm{G \alpha}_{\mathrm{i} 1}$ in inactive form was recorded on HORIBA Jobin Yvon fluorolog spectrometer with excitation light of $295 \mathrm{~nm}$ (excitatoin and emission slit width of $5 \mathrm{~nm}$ ) at $25^{\circ} \mathrm{C}$. In a $3 \mathrm{~mL}$ quartz cuvette, $400 \mathrm{nM} \mathrm{Go}_{\mathrm{i} 1}$ [in $5 \mathrm{mM}$ Hepes-Na (pH 8.0), $10 \mathrm{mM} \mathrm{NaCl}, 0.5 \mathrm{mM} \mathrm{MgCl}_{2}$ and $1 \mu \mathrm{M}$ GDP] was taken and titrated with AuNPs. In all cases blank spectra (buffer containing only AuNP) were subtracted from the protein spectra.

\section{Fluorescence-based kinetic assays}

Time-based fluorescence activity measurements were performed on a Jasco FP-6500 Spectrofluorometer at $25^{\circ} \mathrm{C}$. In a $3 \mathrm{~mL}$ cuvette, $400 \mathrm{nM} \mathrm{G \alpha} \alpha_{\mathrm{i} 1}$ [in $5 \mathrm{mM}$ Hepes (pH 8.0), $10 \mathrm{mM} \mathrm{NaCl}, 0.5 \mathrm{mM} \mathrm{MgCl}_{2}$ and $1 \mu \mathrm{M}$ GDP] was taken. $16 \mu \mathrm{M}$ GTP $\gamma \mathrm{S}$ was added to the protein and the relative increase in intrinsic fluorescence $(\lambda e x=295 \mathrm{~nm}$, $\lambda e m=340 \mathrm{~nm})$ was measured as a function of time. Similar measurments were performed for AuNP conjugated $\mathrm{G \alpha}_{\mathrm{i} 1}$. GTP $\gamma \mathrm{S}$ exchange rates were determined as described elsewhere [35]. FRET was monitored by exciting the intrinsic Trp fluorescence at $295 \mathrm{~nm}$ and measuring the mant-GTP fluorescence at $448 \mathrm{~nm}$. In all cases, blank spectra containing buffer alone were subtracted from the final spectra.

\section{Circular dichroism (CD) spectroscopy}

CD measurements were made on a JASCO model J-715 spectropolarimeter. Far-UV-CD spectra were recorded in $1 \mathrm{~cm}$ path length cuvette from 200 to $260 \mathrm{~nm}$; each spectrum was the average of 5 scans. Spectra were recorded with the final protein concentration of $100 \mu \mathrm{g} / \mathrm{mL}$. 
Appropriate buffer spectra were recorded and subtracted from the protein spectra.

\section{Data analysis}

The apparent rate constants (kapp) reported (Table 1, 2, 3) is the mean of several independent experiments and represent kapp $\times 10^{-3} \mathrm{sec}^{-1}$. Initial 1000 (for non-covalent conjugation) and 200 (covalent conjugation) data points were used to calculate the apparent rate constants reported. In Table 4, the apparent rate constants (kapp) reported is the mean of several independent experiments and represents kapp $\mathrm{x}-10^{-4} \mathrm{sec}^{-1}$. The -fold change in the rate of the AuNP- $G \alpha_{i 1}$ to that of $G \alpha_{i 1}$ is calculated as kapp (AuNP- $\left.G \alpha_{i 1}\right) / k a p p\left(G \alpha_{i 1}\right)$.

\section{Additional files}

\begin{abstract}
Additional file 1: Figure S1. (A) Bioconjugation of AuNP-DHLA to Gai1 via EDC resulting in a covalent linkage. Agarose gel (2\%) of gold nanoparticles with and without proteins attached to them. Lane1: AuNP (control), Lane (2): AuNP + EDC (negative control), Lane (3), (4), (5): covalently conjugated AuNP- Gai1 with 100, 200, 300 MM Gai1 respectively. Retardation in electrophoretic mobility in lanes (3), (4) and (5) is attributed to formation of bioconjugates. AuNP in presence of EDC (Lane 2) also showed little retardation in mobility even when no protein was present. This could be explained by formation of O-acylisourea intermediates formed between AuNP and EDC. (B) Bioconjugation of AuNP-DHLA to Gai1 via non-covalent interaction. Lane (1): AuNP (control), Lane (2): AuNP- Gai1 (electrostatic interaction), Lane (3): AuNP-Gai1 where Gai1 Cysteines were modified by lodoacetamide before conjugation. Retardation in electromobility in lanes (2) and (3) confirms bioconjugation. No difference in mobility in lanes (2) and (3) rules out thiol-AuNP interaction.
\end{abstract}

Additional file 2: S2. Cysteine modification: lodoacetamide was used to derivatize cysteines in Gai1. $50 \mu \mathrm{L}, 100 \mu \mathrm{M}$ Gai1 was incubated with $10 \mu \mathrm{L}, 100 \mathrm{mM}$ lodoacetamide (in $5 \mathrm{mM}$ Hepes-Na, $\mathrm{pH}$ 8.0) for 15 minutes at $25^{\circ} \mathrm{C}$. Complete cysteine alkylation was monitored by 5,5'-dithiobis-(2-nitrobenzoic acid) [DTNB] assay. Standard plot was obtained using Gai1 from 1-10 $\mu \mathrm{M}$. To check for free cysteine groups in AuNP conjugated Gai1 fluorescence adducts were formed with $\mathrm{N}$-(3-pyrene) maleimide and emission spectra was recorded with Excitation light of $345 \mathrm{~nm}$.

Additional file 3: Figure S3. Far UV Circular Dichroism (CD) spectra of AuNP- Gai1 conjugates. (A) Displays far-UV CD spectra of non-covalently conjugated AuNP-Gai1. The solid line represents 400 nM Gai1 only (without AuNP); Dotted line represents 400 nM Gai1 with 0.6 nM AuNP; dash-dash-dash line represents 400 nM Gai1 with 1 nM AuNP. (B) Displays far-UV CD spectra of N-terminal covalently conjugated AuNP- Gail

Additional file 4: S4. Synthesis protocol of AuNP. In brief, $462.62 \mathrm{mg}$ Didodecyldimethylammonium bromide (DDAB) was dissolved in $10 \mathrm{~mL}$ toluene and $86.135 \mathrm{mg}$ decanoic acid was dissolved $5 \mathrm{~mL}$ toluene to give stock solution of $100 \mathrm{mM}$. Gold precursor solution (25 mM) was prepared by dissolving $6.8 \mathrm{mg}$ of gold (III) chloride (AuCl3) in $0.8 \mathrm{~mL}$ $100 \mathrm{mM}$ DDAB solution. In a typical synthesis, $1 \mathrm{ml}$ of freshly prepared Tetrabutylammonium borohydride (TBAB) solution $(25.73 \mathrm{mg}$ in $1 \mathrm{~mL}$ of DDAB solution) was mixed with $0.625 \mathrm{ml}$ decanoic acid stock solution under vigorous stirring and $0.8 \mathrm{ml}$ gold precursor solution was injected leading instantaneously to a dark-red solution of Gold nanoparticles (AuNPs) capped with DDAB. After two hours the solution was centrifuged (2500 rpm, $30 \mathrm{~min}$ ) to remove free surfactants, reducing agents and smaller nanoparticles. The precipitate of AuNPs was then re-dissolved in $2.5 \mathrm{ml}$ DDAB stock solution. Ligand exchange: To a $2.5 \mathrm{~mL}$ solution of AuNP-DDAB freshly reduced $0.104 \mathrm{mg}$ lipoic acid (LA) was added and stirred until no bubbles generated. The brown precipitate of AuNP-DHLA was purified by washing with toluene and chloroform and all solvents were evaporated. Addition of $5 \mathrm{~mL}$ of $0.1 \mathrm{M} \mathrm{NaOH}$ caused deprotonation of the $\mathrm{COOH}$ groups of the dried AuNP-DHLA and thus rendering the AuNP soluble in the water phase. The gold nanoparticles were purified by passing through the membrane of a $30 \mathrm{KDa}$ molecular weight cut-off (MWCO) centrifuge filter (Millipore) and the particles were concentrated, followed by buffer exchange.

Additional file 5: Figure S5. High resolution Transmission electron microscopic (HRTEM) images of AuNP-DHLA. Sample was diluted and directly added on carbon-coated copper TEM grids and the solvent evaporated to form a dry particle film. Images confirm very narrow size distribution. Scale bar corresponds to $50 \mathrm{~nm}, 20 \mathrm{~nm}, 5 \mathrm{~nm}$ for panel A, B and C respectively. 50 particles were randomly selected and size distribution was measured using Image-J software, resulting in $5.92 \mathrm{~nm} \pm 0.5219$ in diameter.

Additional file 6: Figure S6. Surface plasmon resonance of AuNP. UV-vis absorption spectra of the as-prepared gold nanoparticles (AuNP-DDAB, dotted lines) and after ligand exchange (AuNP-DHLA, solid line). Au samples with DDAB capping were dissolved in toluene, sample with DHLA capping in aqueous solution. AuNP capped with DDAB showed strong plasmon resonance in the range of $520-530 \mathrm{~nm}$. Plasmon resonance was preserved after ligand exchange with DHLA. This confirms stability of AuNP in aqueous medium.

Additional file 7: S7. Purification of Gai1 protein. Cells were grown at $37^{\circ} \mathrm{C}$ to $\mathrm{A} 600 \mathrm{~nm}$ of $\sim 0.7$ and then induced with $100 \mu \mathrm{M}$ isopropyl- $\beta-\mathrm{D}$ thiogalactoside (IPTG). The culture was then grown for 16 hours at $23^{\circ} \mathrm{C}$. Cells were harvested by centrifugation, and the resulting pellets were resuspended in a buffer containing $20 \mathrm{mM}$ Tris- $\mathrm{HCl}(\mathrm{pH} 8.0), 300 \mathrm{mM}$ $\mathrm{NaCl}, 2 \mathrm{mM} \mathrm{MgCl}$, $10 \mu \mathrm{M}$ GDP. For purification, the cells were sonicated using an ultrasonicator (Vibracell Sonics and Materials, Inc. Newtown, $\mathrm{CT}$, USA). The lysate was centrifuged at $4^{\circ} \mathrm{C}$ (45 $\mathrm{min}$ at $12,000 \mathrm{rpm}$ ). The resulting supernatant was loaded onto a nickel nitrilotriacetic acid (Ni-NTA) Superflow resin column (Qiagen, Hilden, Germany) that was equilibrated with 20 mM Tris- $\mathrm{HCl}$ (pH 8.0), 300 mM NaCl, 2 mM MgCl2, $10 \mu \mathrm{M}$ GDP buffer. The protein loaded resin was washed with 10 column volumes with wash buffer 1 [20 mM Tris- $\mathrm{HCl}$ (pH 8.0), $300 \mathrm{mM} \mathrm{NaCl}$, $2 \mathrm{mM} \mathrm{MgCl}$, $10 \mathrm{mM}$ imidazole] and then with 5 column volume with wash buffer 2 [20 mM Tris- $\mathrm{HCl}$ (pH 8.0), $300 \mathrm{mM} \mathrm{NaCl}, 2 \mathrm{mM} \mathrm{MgCl}$, $30 \mathrm{mM}$ imidazole]. The bound protein was eluted with 2 column volumes of elution buffer [20 mM Tris- $\mathrm{HCl}(\mathrm{pH}$ 8.0), $300 \mathrm{mM} \mathrm{NaCl}, 2 \mathrm{mM}$ MgCl2, $10 \mu \mathrm{M}$ GDP 300 mM imidazole]., were pooled and concentrated to a volume of $1 \mathrm{~mL}$ and loaded onto a Superdex 200 26/60 column (GE Healthcare) that was equilibrated in buffer $[5 \mathrm{mM}$ Hepes- $\mathrm{Na}(\mathrm{pH} 8.0)$, $10 \mathrm{mM} \mathrm{NaCl}, 0.5 \mathrm{mM} \mathrm{MgCl}$, $1 \mu \mathrm{M}$ GDP]. After elution, the proteincontaining fractions were pooled, concentrated and stored at $-80^{\circ} \mathrm{C}$.

\section{Competing interests}

The authors declare that they have no competing interests.

\section{Authors' contribution}

SPN and GKA designed research; SV performed research; SV, SPN and GKA analyzed data; and SV, SPN and GKA wrote the paper. All authors read and approved the final manuscript.

\section{Acknowledgements}

Authors acknowledge funding form the Department of Biotechnology (Govt. of India), New Delhi and IIT Madras for providing facilities. We thank Prof. G. Jayaraman, VIT Univeristy, Vellore, INDIA for allowing us to use CD spectrometer.

Received: 10 October 2012 Accepted: 6 March 2013 Published: 19 March 2013

\section{References}

1. R-Genger U, Grabolle M, C-Jaricot S, Nitschke R, Nann T: Quantum dots versus organic dyes as fluorescent labels. Nat Methods 2008, 5:763-775.

2. Wilson R: The use of gold nanoparticles in diagnostics and detection. Chem Soc Rev 2008, 37:2028-2045. 
3. Michalet X, Pinaud F, Lacoste TD, Dahan M, Bruchez MP, Alivisatos AP, Weiss S: Properties of Fluorescent Semiconductor Nanocrystals and their Application to Biological Labeling. Single Mol 2001, 2:261-276.

4. Parak WJ, Gerion D, Pellegrino T, Zanchet D, Micheel C, Williams SC, Boudreau R, Gros ML, Larabell CA, Alivisatos AP: Biological applications of colloidal Nanocrystals. Nanotechnology 2003, 14:R15-R27.

5. Rosi NL, Mirkin CA: Nanostructures in Biodiagnostics. Chem Rev 2005, 105:1547-1562.

6. Boisselier E, Astruc D: Gold nanoparticles in nanomedicine: preparations, imaging, diagnostics, therapies and toxicity. Chem Soc Rev 2009, 38:1759-1782

7. Cai W, Gao T, Hong H, Sun J: Applications of gold nanoparticles in cancer Nanotechnology. Nanotechnology, Science and Applications 2008, 1:17-32.

8. Popovtzer R, Agrawal A, Kotov NA, Popovtzer A, Balter J, Carey TE, Kopelman R: Targeted Gold Nanoparticles Enable Molecular CT Imaging of Cancer. Nano Lett 2008, 8:4593-4596.

9. Phadtare S, Kumar A, Vinod VP, Dash C, Palaskar DV, Rao M, Shukla PG, Sivaram S, Sastry M: Direct assembly of gold nanoparticle "shells" on polyurethane microsphere "cores" and their application as enzyme immobilization templates. Chem Mater 2003, 15:1944-1949.

10. Zhang C, Zhang Z, Yu B, Shi J, Zhang X: Application of the biological conjugate between antibody and colloid Au nanoparticles as analyte to inductively coupled plasma mass spectrometry. Anal Chem 2002, 74:96-99.

11. Everts $M$, Saini V, Leddon JL, Kok RJ, Stoff-Khalili M, Preuss MA, Millican CL, Perkins G, Brown JM, Bagaria HD, Nikles E, Johnson DT, Zharov VP, Curiel DT: Covalently linked Au nanoparticles to a viral vector: Potential for combined photothermal and gene cancer therapy. Nano Lett 2006, 6:587-591.

12. Ao L-M, Gao F, Pan BF, Cui DX, Gu HC: Interaction between gold nanoparticles and bovine serum albumin or sheep antirabbit immunoglobulin G. Chin J Chem 2006, 24:253-256.

13. Pissuwan D, Valenzuela SM, Miller CM, Cortie MB: A golden bullet? selective targeting of toxoplasma gondii tachyzoites using antibodyfunctionalized gold nanorods. Nano Lett 2007, 7:3808-3812.

14. Gole A, Dash C, Soman C, Sainkar SR, Rao M, Sastry M: On the preparation, characterization, and enzymatic activity of fungal protease-Gold colloid bioconjugates. Bioconj Chem 2001, 12:684-690.

15. Phadtare S, Vinod VP, Mukhopadhyay K, Kumar A, Rao M, Chaudhari RV, Sastry M: Immobilization and biocatalytic activity of fungal protease on gold nanoparticle-loaded zeolite microspheres. Biotechnol Bioeng 2004, 85:629-637.

16. Yang PH, Sun X, Chiu JF, Sun H, He QY: Transferrin-mediated gold nanoparticle cellular uptake. Bioconj Chem 2005, 16:494-496.

17. Demers LM, Östblom M, Zhang H, Jang N-H, Liedberg B, Mirkin CA: Thermal desorption behavior and binding properties of DNA bases and nucleosides on gold. J Amer Chem Soc 2002, 124:11248-11249.

18. Li H, Rothberg L: Detection of specific sequences in RNA using differential adsorption of single-stranded oligonucleotides on gold nanoparticles. Anal Chem 2005, 77:6229-6233.

19. Klein J: Probing the interactions of proteins and nanoparticles. Proc Nat Acad Sci USA 2007, 104:2029-2030.

20. Cedervall T, Lynch I, Lindman S, Berggard T, Thulin E, Nilsson H, Dawson KA, Linse S: Understanding the nanoparticle-protein corona using methods to quantify exchange rates and affinities of proteins for nanoparticles. Proc Natl Acad Sci USA 2007, 104:2050-2055.

21. Linse S, C-Lago C, Xue W-F, Lynch I, Lindman S, Thulin E, Radford SE, Dawson KA: Nucleation of protein fibrillation by nanoparticles. Proc Natl Acad Sci USA 2007, 104:8691-8696.

22. Bhattacharyya S, Bhattacharya R, Curley S, McNiven MA, Mukherjee P: Nanoconjugation modulates the trafficking and mechanism of antibody induced receptor endocytosis. Proc Natl Acad Sci U S A 2010, 107:14541-14546.

23. Niemeyer CM: Nanoparticles, proteins, and nucleic acids: biotechnology meets materials science. Angew Chem Int Ed 2001, 40:4128-4158.

24. Tedescoa AC, Oliveiraa DM, Lacavab ZGM, Azevedob RB, Limac ECD, Moraisd PC: Investigation of the binding constant and stoichiometry of biocompatible cobalt ferrite-based magnetic fluids to serum albumin. J Magn Magn Mater 2004, 272-276:2404-2405.

25. Lynch I, Dawson KA: Protein-nanoparticle interactions. Nano Today 2008, 3:40-47.
26. Huo Q: A perspective on bioconjugated nanoparticles and quantum dots. Colloids Surf B Biointerfaces 2007, 59:1-10.

27. Farokhzad OC, Langer R: Impact of nanotechnology on drug delivery. ACS Nano 2009, 3:16-20.

28. Johnston CA, Siderovski DP: Receptor-mediated activation of heterotrimeric G-proteins: current structural insights. Mol Pharmacol 2007 72:219-230

29. Ackerson CJ, Jadzinsky PD, Jensen GJ, Kornberg RD: Rigid, specific, and discrete gold nanoparticle/antibody conjugates. J Am Chem Soc 2006, 128:2635-2640.

30. Teichroeb JH, Forrest JA, Jones LW: Size-dependent denaturing kinetics of bovine serum albumin adsorbed onto gold nanospheres. Eur Phys J $E$ 2008, 26:411-415.

31. Shang W, Nuffer JH, Dordick JS, Siegel RW: Unfolding of ribonuclease A on silica nanoparticle surfaces. Nano Lett 2007, 7:1991-1995.

32. Lundqvist $M$, Sethson I, Jonsson BH: Protein adsorption onto silica nanoparticles: conformational changes depend on the particles' curvature and the protein stability. Langmuir 2004, 2004(20):10639-10647.

33. Nikhil RJ, Xiaogang P: Single-phase and gram-scale routes toward nearly monodisperse $\mathrm{Au}$ and other noble metal nanocrystals. J Am Chem Soc 2003, 125:14280-14281.

34. Lowry OH, Rosebrough NJ, Farr AL, Randall RJ: Protein measurement with the folin phenol reagent. J Bio Chem 1995, 193:265-275.

35. Fahmy K, Sakmar TP: Light-dependent transducin activation by an ultraviolet-absorbing rhodopsin mutant. Biochemistry 1993, 32:9165-9171.

doi:10.1186/1477-3155-11-7

Cite this article as: Singh et al.: Chemistry of conjugation to gold nanoparticles affects G-protein activity differently. Journal of Nanobiotechnology 2013 11:7.

\section{Submit your next manuscript to BioMed Central and take full advantage of:}

- Convenient online submission

- Thorough peer review

- No space constraints or color figure charges

- Immediate publication on acceptance

- Inclusion in PubMed, CAS, Scopus and Google Scholar

- Research which is freely available for redistribution 